\title{
VERSÕES DE ATLETAS DE MIXED MARTIAL ARTS NAS FASES DE PREPARAÇÃO PARA UM COMBATE
}

\author{
VERSIONES DE ATLETAS DE ARTES MARCIALES MIXTAS \\ EN LAS FASES DE PREPARACIÓN PARA UN COMBATE \\ VERSION ATHLETES OF MIXED MARTIAL ARTS \\ IN THE PREPARATORY STAGES FOR A FIGHT
}

\author{
Juliana Aparecida de Oliveira Camilo ${ }^{1}$ e Mary Jane Paris Spink ${ }^{1}$ \\ ${ }^{1}$ Pontifícia Universidade Católica de São Paulo, São Paulo/SP, Brasil
}

\begin{abstract}
RESUMO: O objetivo desta pesquisa foi identificar as versões de atletas de Mixed Martial Arts (MMA) que circularam nas fases de preparação para um combate (camp). Para isso, seguimos o cotidiano de um atleta, vinculado à principal liga da modalidade, o Ultimate Fighting Championship (UFC), em dezembro de 2014. A metodologia seguiu os pressupostos da etnografia, com interações nas diferentes práticas em que o atleta se envolvia. Adotamos uma aproximação teóricometodológica com a teoria ator-rede, em diálogo com a Psicologia Social de cunho construcionista. Nas fases do camp foi possível identificar as versões de lutador como: (a) trabalhador que é precarizado (treinamentos); b) ídolo (semana da luta); (c) sobrevivente (pesagem); (d) “casca-grossa” (dia da luta); e (e) "humano” (pós-luta). A pesquisa sugere que não há um tipo específico de lutador, ou perspectivas diferentes sobre ele, mas sim, que ele é múltiplo, produtos das práticas nas quais está envolvido.
\end{abstract}

PALAVRAS-CHAVE: Psicologia do esporte; Psicologia social; Etnografia MMA.

RESUMEN: El objetivo de esta investigación fue identificar las versiones de atletas de Mixed Martial Arts (MMA) que circularon en las fases de preparación para un combate (camp). Para esto, seguimos el cotidiano de un atleta, vinculado al principal evento de la modalidad, el Ultimate Fighting Championship (UFC), en diciembre de 2014. La metodología siguió los presupuestos de la etnografía, con interacciones en las diferentes prácticas en que el atleta se involucró. Adoptamos una aproximación teórico-metodológica con la teoría actor-red, en diálogo con la Psicología Social de cuño construccionista. En las fases del camp fue posible identificar las versiones de luchador como: (a) trabajador que es precarizado (entrenamientos); (b) ídolo (semana de la lucha); (c) superviviente (pesaje); (d) "cáscara gruesa” (día de la lucha); y (e) "humano" (post-lucha). La investigación sugiere que no hay un tipo específico de luchador, o diferentes perspectivas sobre él, sino que es múltiple, producto de las prácticas en las que está involucrado.

PALABRAS CLAVE: Psicología del deporte; Psicología social; Etnografía MMA.

ABSTRACT: The aim of this research was to identify the versions of Mixed Martial Arts (MMA) athletes that circulated in the stages of preparation for a fight (camp). With this purpose, we followed the daily life of an athlete of a major league of the sport, the Ultimate Fighting Championship (UFC), in the year 2014. The methodology followed the postulations of ethnography, with interactions in the different practices in which the athlete was involved. We adopted the theoretical and methodological approach of actor-network theory, in dialogue with Social Psychology. In phases of the camp it was possible to identify the following versions of the athlete: a) worker in precarious conditions (training); b) idol (in the week of event); c) survivor (weighing); d) "thick-skinned" (on the day of the fight); and e) "human" (post-fight). Research suggests that there is not a specific type of wrestler or different perspectives on it: he is multiple, a result of the practices in which he is involved.

KEYWORDS: Sport Psychology; Social psychology; MMA Ethnography. 


\section{Introdução}

O Mixed Martial Artes (MMA) é uma luta que emprega técnicas corporais de várias artes marciais e/ou esportes de combate, tais como o Jiu-Jitsu, Boxe, Kickboxing, Muai Thay, luta greco-romana, Kung Fu, Karatê, Capoeira, Judô, entre outras (Awi, 2012; Alonso \& Nagao, 2013; Franchini \& Vecchio, 2011). A competição se dá em um ringue quase sempre rodeado por grades, que dá a sensação de jaula, sendo o formato mais conhecido chamado de Octógono. Como a modalidade tem categorias baseadas no peso de seus atletas, antes das lutas ocorrem, eles sobem à balança para checagem do seu peso e, nesse momento, os meios de comunicação tentam criar um clima de rivalidade e agressividade característica de espetáculo. Espera-se que os lutadores demonstrem suas habilidades em diferentes artes marciais, vençam o combate e, sobretudo, conquistem o público com sua performance no combate, o desempenho apresentado, assegurando-lhes um lugar de destaque entre os demais lutadores (Wells, 2012).

De acordo com Awi (2012), o vale-tudo começou na terceira década do século XX, quando Carlos Gracie, um dos fundadores da arte marcial brasileira, conhecida como "Gracie jiu-jitsu", começou a convidar um competidor de cada modalidade distinta de luta para participar do mesmo evento. Isso era chamado de "Desafio do Gracie". Mais tarde, Hélio Gracie e a família Gracie e, principalmente, Rickson Gracie mantiveram este desafio, que passou a ocorrer como duelos de vale-tudo sem a presença da mídia. As artes marciais mistas também obtiveram grande popularidade nos Estados Unidos, em 1993, quando Rorion Gracie e outros sócios criaram o primeiro torneio de Ultimate Fighting Championship (UFC).

O evento recém-criado tinha forte apelo para o inusitado e se assemelhava mais a um freak show do que a uma modalidade esportiva. O planejamento das lutas, o narrador, a música e outros diversos aparatos tecnológicos eram (e o são) usados para potencializar a emoção dos envolvidos (telespectadores, lutadores, comissão técnica, fãs, patrocinadores), desde a divulgação do evento até o balanço midiático pós-evento. Esta é a versão de MMA como espetáculo que foi explorada em estudo anterior (Camilo \& Spink, 2018).

Para Caillois (1990), teríamos nesse sentido o mimicry, que pressupõe uma aceitação temporária de uma ilusão, tanto pelo ator, quanto pela plateia. Há uma encarnação de um personagem ilusório e a adoção de comportamentos que o ilustram. As diferentes manifestações expressivas têm como característica o fato de a pessoa fazer crer a si própria, ou aos outros, que ela seria outra pessoa. Para que essa ilusão seja possível usa-se mímica e disfarces, que ajudam o ator a esquecer temporariamente de si. A questão aqui não está no prazer em ludibriar o espectador, mas no prazer obtido por meio do jogo com a encenação de diferentes papéis. A regra desse jogo consiste em fascinar o espectador, levando-o a uma ilusão. Ao espectador cabe a aceitação dessa ilusão, deixando-se levar pela crença, num dado tempo e cenário, de que há uma realidade sendo ali apresentada.

De um modo geral, o esporte foi transformado em espetáculo desde a segunda metade do Século XX, sobretudo por meio da multiplicação dos meios de comunicação, em que o esporte passou do amadorismo para o profissionalismo, impondo a seus protagonistas uma mutação de papéis (Rubio, 2018). Também é possível posicionar o MMA como um "esporte de risco-aventura" (Spink, Medrado, \& Mello, 2002), seguindo a equação: quanto mais aventura, mais adrenalina; quanto mais exposição ao perigo, mais espetáculo, mais fãs, mais prestígio, mais patrocinadores, mais dinheiro. 
Toda essa lógica aponta também para o fato de o esporte de alto-rendimento ter se convertido em um mercado qualificado e exigente, tanto em seu aspecto técnico (aperfeiçoamento dos movimentos) quanto do ponto de vista econômico (o nome de alguns atletas movimenta o consumo de importantes conglomerados). Com isso, vê-se que os atletas de diferentes modalidades são trabalhadores (Bourdieu, 1983; Caillois, 1990; Wacquant, 2000), ou seja, pessoas que, como os diferentes indivíduos assalariados inseridos em uma lógica tradicional, vendem o seu tempo, a sua habilidade, emprestam os seus corpos, nomes e subjetividades para um determinado fim.

Por isso já não é possível pensar estes humanos que competem como amateur, tal como postulado por Pierre Coubertin e discutido por Bourdieu (1983) e Rubio (2010). Na atualidade, podemos pensar também que há, inclusive, um seleto grupo de atletas de alto-rendimento, vinculados aos grandes conglomerados esportivos e que possuem contratos milionários, sendo empresários de si, em um funcionamento semelhante às pequenas, médias e grandes empresas.

Consonante a essa discussão, Bracht (2005) aponta que o esporte de alto rendimento foi transformado em mercadoria, assumindo as características do setor produtivo ou de prestação de serviços, refletindo nos intensos apelos à profissionalização dos dirigentes esportivos e na administração empresarial dos clubes (empresas). Estaria aqui em xeque parte do imaginário social que associa o esporte a uma atividade estéril, sem utilidade e executada para e pelo prazer (Rubio, 2001).

Por este motivo, uma importante sinalização do sucesso empresarial esportivo está vinculada ao número de consumidores vinculados à modalidade. Não há estimativas confiáveis que apontem o número de praticantes do MMA no Brasil, mas, de acordo com a consultoria Deloitte (2011), em pesquisa de opinião sobre as tendências esportivas no país em decorrência dos eventos esportivos sediados pelo Brasil (Copa do Mundo e Olímpiadas), as Artes Marciais foram consideradas o segundo esporte que mais iria crescer neste período.

No Brasil, é possível observar o desenvolvimento do MMA, que ganhou espaço no cenário esportivo e na mídia, conquistando um número crescente de interessados, fãs, praticantes e patrocinadores. Isso levou ao desenvolvimento de produtos esportivos e a organização de novos eventos. Corroborando essa ideia, apenas em 2014, foram localizadas 312 ligas no país que realizaram eventos (Camilo, 2016). Estas ligas são registradas como empresas, podendo atrair investidores, patrocinadores e incentivos governamentais. Com isso, vemos que, mais do que um esporte, o MMA se tornou um grande negócio, envolto em interesses mercadológicos tanto do atleta, que vê no esporte um futuro profissional (que pode ajudá-lo a ascender financeiramente), quanto para seus investidores, que esperam retornos financeiros.

No cenário internacional, Ultimate Fighting Championship (UFC) é a principal liga de MMA e tem faturamentos que impressionam. O UFC também compõe o seleto grupo da revista Forbes, que avalia as marcas esportivas mais valiosas no mundo. De acordo com este ranking, em 2014, a empresa valia 1.65 bilhões de dólares, e sua marca, 440 milhões (Ozanian, 2014). Contudo, já em julho de 2016, o UFC foi vendido por 4 bilhões de dólares (cerca de 13 bilhões de reais) para o grupo chinês William Morris Endeavor (IMG). O acordo é possivelmente a maior venda de uma franquia esportiva (Merced, 2016).

Com o crescente interesse do público, os atletas precisam buscar a superação contínua, para que consigam se destacar e serem contratados para os eventos de maior evidência. Tem-se aqui uma relação mercadológica estabelecida: quando melhor a performance do atleta, maior pode ser sua remuneração e os convites recebidos para lutar. As lutas tornam-se cada 
vez mais intensas. Os eventos cada vez mais tecnológicos, onde o atleta parece muitas vezes assumir a posição de um personagem de video game: com feições agressivas, apelidos curiosos, vestimentas estereotipadas, plasticidade de golpes e força nos movimentos.

Nessa direção, alguns estudos discutem os riscos envolvidos na prática deste esporte. Para Kochhar, Back e Mann (2005), existe um risco significativo de lesões cervicais, sendo que não há normas de segurança para abordar tais preocupações. Bledsoe, Hsu, Grabowski, Brill e Li (2006) analisaram 171 eventos envolvendo 220 diferentes lutadores de MMA, entre setembro de 2001 e dezembro de 2004, no estado de Nevada (EUA). Neste estudo foi constatado um total de 96 lesões em 78 lutadores. Dos 171 eventos de luta, 69 (40,3\%) terminou com pelo menos um lutador ferido. A lesão facial foi a mais comum, correspondendo por $47,9 \%$ de todas as lesões, seguido por lesão na mão (13,5\%), lesão no nariz (10,4\%) e lesões oculares (8,3\%). Bernick et al. (2012) discutem os riscos dos traumas repetitivos na cabeça dos atletas como um importante fator para o desenvolvimento da doença de Alzheimer, além de outros comprometimentos das funções cognitivas. Assim se pergunta: quem são os praticantes de um combate tão intenso como o MMA?

Como referencial teórico-metodológico, adotamos o construcionismo social em interlocução com a Teoria Ator-Rede (TAR) para desenvolvimento da pesquisa. A TAR é uma corrente de pensamento utilizada desde 1997 em publicações na área da Psicologia, com especial ênfase na Psicologia Social. Seus principais questionamentos versam sobre as bases epistemológicas advindas da tradição científica experimentalista moderna, problematizando ainda a centralidade do ser humano como foco e origem do conhecimento (Méllo, Spink, \& Mincoff, 2016). Trata-se de uma corrente de pensamento que pode contribuir significativamente para as práticas em Psicologia, sobretudo para a construção de uma Psicologia do Esporte menos essencialista e menos preocupada com o desempenho atlético, já que parte de um estranhamento com o instituído, problematizando as relações de poder, assim como a produção e manipulação do conhecimento.

Assim, ontologicamente e epistemologicamente temos: a compreensão de que as realidades são múltiplas e construídas em práticas, a importância dos humanos e dos não-humanos nessa construção, a ruptura com as dicotomias interior-exterior, sujeito-objeto e mente-corpo. É importante salientar que, para a Teoria Ator-Rede, tanto as pessoas quanto os objetos criam realidades e estabelecem redes de conexões, constituindo-se como mediadores das associações sociais, o que abala a tradicional divisão entre ação humana e causalidade material. Nesse sentido, os objetos não estariam reduzidos ao domínio da passividade, sob a supremacia dos humanos, mas sim em uma relação simétrica na produção do conhecimento (Latour, 2000). Assim, as versões não são apenas dispositivos discursivos, mas sim produtos de materialidades e sociabilidades (Law \& Mol, 2008).

Assume-se, assim, a postura de seguir uma ontologia empírica, em que os diferentes elementos ganham sentidos à medida que se inserem em práticas (Cordeiro \& Spink, 2014; Law \& Mol, 2008). Para Law (2002), o objeto adquire existência e sentido apenas quando uma rede razoavelmente estável de humanos e não-humanos também possam existir. Assim, os sentidos dos termos dependem de relações e, principalmente, das diferentes relações entre si. Um objeto continuará a ser o mesmo enquanto tudo permanece no mesmo local de modo estável. Se de algum modo o circuito for quebrado, o objeto perderá a sua forma e mudará sua configuração.

É fundamental também a diferenciação entre a multiplicidade e a diversidade. Na diversidade, o objeto permanece único, o que pode mudar são olhares sobre ele, apontando 
para várias visões, que não se articulam necessariamente entre si. Tal visão se aproxima do perspectivismo. Já na multiplicidade, é o objeto que passa a existir de modos distintos, a posteriori das práticas, independente dos olhares sobre ele, sendo que esses objetos não estão totalmente desconectados, pois, na multiplicidade, tem-se o que é diverso e ao mesmo tempo singular. É o que Mol (2002) chama de objeto fractal. Em outras palavras, dizer que o lutador de MMA é múltiplo não significa dizer que suas versões não estejam agrupadas, pois elas possuem sempre alguma relação.

\section{Metodologia}

Na linguagem do MMA, um camp é o nome usado para designar um período de treinamento e atendimento multiprofissional (psicólogo, nutricionista, fisioterapeuta), que geralmente compreende entre 6 a 8 semanas antes de uma luta, para que o atleta atinja o ápice de seu rendimento. Para entender quem é esse atleta, acompanhamos o camp de Marcelo (nome fictício), durante as 8 semanas anteriores ao seu combate, o dia da luta e o pós-luta. Esse estudo seguiu a inspiração etnográfica empregada por Latour (2000), Mol (2002), Law e Mol (2008). Nesta vertente, só é possível problematizar quem são os atletas de MMA associando-os com as práticas em que eles estiveram envolvidos.

De modo a entender essas práticas, foram adotadas várias estratégias, como a observação participante e as conversas (espontâneas ou intencionalmente estimuladas). Foi possível seguir Marcelo nas práticas que nos foram autorizadas a conhecer: treinamentos, reuniões de grupo, gravação de vídeos, autógrafos, procedimentos diversos para perder peso, recuperação após a pesagem, acompanhamento no dia da luta e conversas posteriores à luta. Para ordenar todo material coletado durante a pesquisa, utilizamos um diário de campo. Nele, descrevemos as práticas que participamos com detalhes, procedimento chamado por Latour (2012) de "descrição densa”.

Um registro sempre implica escolhas, já que não é possível captar todos os acontecimentos. No entanto, os relatos textuais que serão aqui apresentados não são filtrados com interpretações, já que a concepção é de que a descrição possa falar por si só e que, se precisar ser explicada, não será uma boa descrição (Latour, 2012). Seguindo esses pressupostos, as versões que aqui serão descritas foram problematizadas depois das práticas acompanhadas. Para isso, foram feitas leituras e releituras das descrições das conversas e observações contidas no diário de campo.

A pesquisa foi aprovada pelo Comitê de Ética em Pesquisa da Pontifícia Universidade Católica de São Paulo, recebendo o número de parecer 579.937. Para garantia do anonimato, os nomes apresentados são fictícios.

\section{Resultados}

Apresentaremos aqui a preparação para uma luta agendada (treinamentos), a pré-luta, que ocorre uma semana antes do evento, o dia do evento, com as ações que envolveram o combate, e o pós-luta. Serão expostas as experiências que envolveram o lutador Marcelo, do UFC, que abriu as portas para que tal estudo fosse possível. As descrições das práticas que acompanhamos sugeriram que as versões foram: (a) trabalhadores invisíveis e precarizados 
(treinamentos); (b) lutadores-ídolo (semana da luta); (c) sobreviventes da pesagem (um dia antes da luta); (d) "cascas-grossa” (dia da luta) e; (e) "humanos-comum” (pós-luta).

\section{Os trabalhadores precarizados do treinamento}

O cotidiano de treinamento dos atletas implica o uso do corpo no limite da lesão e o convívio diário com a dor. Não há espaço para lamentos e há falta de recursos fundamentais: alimentação adequada, assistência médica, descanso entre treinamentos e outras atividades profissionais (como dar aula, venda de produtos diversos, promoção de eventos). Um trabalhador deveria cumprir suas tarefas, chegar no horário, ter foco em suas ações, ser eticamente correto com os demais atletas e com a equipe técnica. Deveria se orgulhar de sua equipe, levando o nome da academia aos eventos esportivos. Nesse sentido, o "tique-taque" do relógio assumia um papel fundamental, já que é era quem sinalizava a necessidade de treinamento contínuo.

Marcelo: "Cada dia é uma luta. Cada dia sei que tenho que dar o meu melhor, porque isso aqui é meu trabalho. É daqui que tiro o sustento da minha família. Sei que, se bobear, o UFC não terá pena de mim. Olha quantos já foram demitidos. Por isso, não vacilo. Todo dia é dia de guerra”.

Juliana: "Pensei que você não fosse treinar hoje. Você havia me falado que estava com muita dor na mão".

Marcelo: "E estou, doutora. Olha aqui (me mostra a mão inchada). Mas se eu não treinar, sei que meu adversário está lá treinando e melhorando. No MMA não dá para ficar doente. Tem que treinar. Tem que trabalhar duro”. (Academia B, Diário de Campo, outubro de 2014).

Como tolerar um trabalho que implica o uso do corpo no limite da lesão, com o medo da derrota ou com o medo de ser demitido? Mas os atletas são trabalhadores? Pierre Bourdieu (1983) e Löic Wacquant (2000, 2002) avançaram nessa problemática ao relacionarem a atividade esportiva com a geração de valor econômico e a exploração do trabalho, tal como ocorre em outras categorias profissionais.

Esta é a lógica posta nos treinamentos de Marcelo. As feições de dor são claras, ao mesmo tempo em que se tentava demonstrar que estava tudo certo, que era "apenas" uma lesão "normal”, que poderia ser domada. O atleta precisava lutar, já que apenas a partir da luta conseguiria ganhar um prêmio maior em dinheiro e custear sua vida.

Marcelo tinha uma fala reivindicatória. Ele era um trabalhador e se reconhecia como tal, assumindo essa crítica também para as práticas da academia em que atuava. Nesse espaço, o atleta era um trabalhador, possuía um alojamento para dormir, uma vida regrada e cerceada com avaliação diária do seu desempenho e feedbacks constantes. Embora no camp estudado houvesse um reconhecimento por parte do atleta de seu trabalho, o mesmo não estava autorizado a militar publicamente contra a comercialização do seu corpo e sua vida, ou seja, não se podia evidenciar a falta dos elementos não-humanos que minimamente o protegeriam perante a organização de trabalho: um contrato com regras claras e o registro na carteira profissional. Ele era um iniciante em uma organização mundialmente 
poderosa e, reivindicar o status de trabalhador e denunciar sua exploração, poderia fazê-lo perder o seu contrato.

A fala do lutador foi anotada oito semanas antes de seu combate, quando ele havia conseguido um tempo considerado "ótimo" para seu treinamento. Aquele fora apenas mais um dia de trabalho para Marcelo, em que ele conviveria com o medo da derrota, com o desejo da vitória, com as inúmeras dores no corpo, com as preocupações financeiras e com a contradição de que, em breve, entraria em um mundo com vários elementos físicos que sinalizavam luxo e glamour na semana do combate.

Marcelo obedecia a uma vida regrada e cerceada. "Pode isso, não pode aquilo". As dúvidas eram esclarecidas com os especialistas (treinadores, médico, fisioterapeuta, nutricionista). Era ainda uma fase em que podia se permitir pequenas subversões, dentre elas, comer doces e pizza. Porém, baixar mais de 20 quilos até o combate era uma de suas principais tarefas e preocupações, por isso mantinha um enfrentamento diário com as marcações da balança. Era ela quem apontaria o que seria feito: comer mais ou menos, fazer mais treinamentos físicos, tomar mais ou menos água.

"Marcelo é um cara muito comprometido. Seu treino rende muito, porque ele é muito focado", informou o doutor Hugo, líder da academia em que Marcelo atuava, a seis semanas do combate. Foco, disciplina, rendimento e comprometimento. Elementos que compõem o cotidiano de diversos outros trabalhadores.

A avaliação do desempenho também estava presente nos treinamentos, sobretudo quando o combate estava se aproximando. Quantos golpes foram deferidos em "X" intervalo de tempo, a melhoria na execução de um movimento e até se os olhos demonstravam vigor. "Veja, Doutora, ele nem pisca. Está focado!", disse-me Antonio, o treinador principal, a duas semanas da luta.

Marcelo morava na academia, em um local apelidado de "mansão". Seu quarto era pequeno e possuía uma cama, uma mala com algumas roupas, uma cadeira de plástico, um ventilador e uma cortina para tapar a luz do sol pela manhã. A cortina era seu luxo, como gostava de dizer, já que odiava a claridade da manhã. A mansão ganhava ares de alojamento, semelhante a outras categorias profissionais que necessitam de estadia, tendo em vista que os trabalhadores moravam distante de suas residências ou por precisarem permanecer próximo ao trabalho. Certamente não havia conforto nas instalações (sanitários, vestiários e refeitórios), como exige a Norma Regulamentadora 24 (NR-24, 1993), mas isso parecia contar pouco. O que valia era estar próximo ao trabalho, concentrado e com foco para a luta.

\section{O lutador-ídolo na semana da luta}

A semana da luta é um momento muito especial. Paira um clima de tensão, de êxtase e dúvida. Fotos, vídeos, abraços apertados e elogios a todo instante. Os lutadores ficam hospedados em um hotel pago pela organização do evento. Nele, há muitos seguranças, protegendo os hóspedes, os lutadores, a comissão técnica e a imprensa. Mas não parecia ser apenas essa a função dos seguranças, já que eles davam status, glamour e endossavam a importância daquele local, quase que "sagrado".

Na primeira interação feita nesse espaço, Marcelo aparece na recepção e é imediatamente interceptado por um homem jovem, pedindo para que desse um autógrafo em uma camiseta. Gentilmente, Marcelo autografou, tirou fotos, brincou com algum assunto tri- 
vial e se despediu do fã. Veio em minha direção, me cumprimentou e, quando ia começar a falar algo, uma promotora o interrompeu sem cerimônias, informando que ele deveria seguir a agenda programada. Marcelo teria uma série de compromissos e deveria cumprir a todos, seguindo rigorosamente o roteiro.

É nesse momento que um jornalista invade a cena, já que precisava que Marcelo desse uma entrevista. A câmera foi ligada, o jornalista olha a aparência do lutador e pergunta se ele estava pronto. O atleta brinca com sua nova condição de "ídolo" e diz que era "feio e que não teria tempo para ficar bonito”, consentindo em começar a entrevista. A câmera, esse elemento não-humano que, quando ligada, muda visivelmente as práticas ali presentes e a atuação dos humanos. É a partir da relação entre a abordagem do jornalista e da câmera ali ligada que o lutador tenta se manter alinhado, ainda que sofrendo as inúmeras dores no corpo, ainda tentando perder o peso necessário para se enquadrar na sua categoria do evento. Marcelo tenta escolher as palavras certas, o melhor modo de aparecer para os fãs. Terminada a curta gravação (cerca de dez minutos, ou o "tempo suficiente" na fala do jornalista), o atleta retoma seu semblante de cansaço e caminha para outros novos compromissos: os autógrafos nos cartazes e a filmagem dos highlights (vídeos curtos que são exibidos antes das lutas, no dia do evento).

Na sessão dos autógrafos, fomos a uma sala específica para que o lutador tirasse novas fotos e autografasse cento e trinta cartazes promocionais do evento. Na sala, estavam três homens que trabalhavam animando o público e organizando o evento durante a pesagem e a luta, duas promotoras, alguns membros de comissões técnicas e dois lutadores, sem qualquer sinal de simpatia ou cordialidade. O idioma predominante era o inglês. Quando chegamos ao local, um atleta estava terminando de autografar, e a promotora disse a Marcelo:

Promotora: "Nossa, ainda bem que você já veio. Agora vou ter que "caçar" os outros. É um saco ficar procurando por vocês! Mas eu já avisei a todos, se não assinar até hoje à tarde, vão ter que se entender com o chefe".

Marcelo: “Eu sou legal, né? Já estou aqui!" (brincando). (Sala de apoio do hotel Diário de Campo, dezembro de 2014).

Antes de começar a assinar, os cartazes foram "analisados" por Marcelo e Antônio: "Olha essa assinatura, professor!"; "Que rabisco é esse?”; “Olha esse aqui, ocupou um espaço enorme no cartaz. Quer ficar em evidência”. Algumas fotos foram tiradas enquanto autografava, com sorrisos e postagens nas redes sociais.

Chegamos pontualmente na sala do hotel destinada à gravação dos highlights. Havia uma escala previamente estabelecida, indicando quem deveria gravar em determinado horário. Quase que imediatamente, ao entrar nesse espaço, um assistente tirou as medidas do corpo de Marcelo: altura, envergadura, cintura. Enquanto Marcelo tirava as medidas e trocava de roupa, notamos outro lutador, Elias, que estava sendo filmado naquele momento. Havia quatro trabalhadores cuidando da filmagem: dois cinegrafistas, um assistente e um responsável por cuidar da aparência do atleta. Um profissional responsável pela câmera solicita a Elias que faça mais "cara de mau” e se empolgue mais na filmagem, já que a gravação estava sem "energia”. Eles repetem a gravação, com aparente contragosto de Elias. Novamente o assistente entra em cena, joga água no corpo do atleta para dar a impressão de suor. Novo pedido de empolgação. Elias não parecia estar satisfeito com aquilo, mas será esse vídeo o responsável por criar no público a sensação de que o lutador estava focado e com muita 
energia para o combate. Evidentemente que o vídeo seria, poucas horas depois, formatado graficamente por profissionais especializados para que tal ilusão fosse possível.

Eles finalizam a filmagem e Marcelo entrou em cena. O assistente também jogou água no seu corpo e ele devolveu com um sorriso. Marcelo seguiu as recomendações, e a gravação durou cerca de dez minutos, tendo recebido elogios da equipe de filmagem.

\section{Os sobreviventes da preparação. A pesagem}

As lutas estavam se aproximando e os lutadores estavam visivelmente exaustos. O cerceamento chegava ao limite do suportável e muitos demonstravam já não aguentar perder mais peso/perder mais líquidos do corpo, ouvir recomendações ou seguir uma rotina tão rigorosa. Por isso, muitos deles preferiam ficar longe de suas famílias nesse momento, já que o "mau humor" era a tônica. Marcelo estava visivelmente abatido, olhos fundos lhe davam a aparência de doente. Já não sorria, e quando brincava, o fazia de modo forçado. Já era mais de meio-dia e fazia mais de doze horas que ele não se alimentava ou ingeria líquidos. O relógio com seu "tique-taque" se tornava insuportável para todos, já que ainda faltavam cerca de quatro horas para a pesagem. Na recepção do hotel, o movimento de jornalistas, fãs e trabalhadores do evento era intenso, mas os lutadores, em sua maioria, estavam refugiados nos seus quartos ou tentando tirar ainda mais os líquidos do corpo para atingir determinado peso.

De acordo com Antônio, Marcelo havia feito sua "lição de casa” e já estava no peso correto da categoria, precisava agora apenas aguentar até a pesagem. Para que isso fosse possível, Marcelo vinha, ao longo de seu camp, perdendo gradativamente peso e seguindo sua dieta. Na semana da luta, já no hotel, fazia treinamentos aeróbicos intensos, vestido com pesadas capas de chuva e ingerindo o mínimo possível de líquidos.

Na sauna, na fala de Antonio, Marcelo havia simulado cinco rounds de cinco minutos cada, vestido com uma capa de chuva para conseguir extrair os líquidos do corpo. Para evitar que o liquido voltasse pelos seus poros, seu treinador raspava sua pele com um cartão magnético. Havia um entra e sai da sauna acompanhado da sequência: treina, sua, raspa. Muitos passam mal, vomitam, têm tonturas, desmaiam. Marcelo havia conseguido mais uma vez suportar esse processo e perder cerca de 20 quilos na semana da luta.

O momento da pesagem é tão importante quando o dia do combate, já que nessa prática os lutadores terão que atingir o peso exigido por sua categoria. As narrativas do Marcelo nesse período apontaram para inúmeras privações físicas, dores e lesões no corpo, além da ansiedade pelo combate futuro.

Há um espetáculo montado para o dia da pesagem, com um apresentador que chama os lutadores para a balança, as mulheres que serão as ring girls, além do executivo responsável pelo evento de MMA. O público marcou a presença na pesagem que acompanhamos, em especial os torcedores mais aficionados, já que ela ocorreu em uma sexta-feira em horário comercial, dificultando o acesso daqueles que pretendiam apenas assistir aos combates. Normalmente, a pesagem é gratuita e, em alguns casos, há distribuição antecipada de ingressos.

Os lutadores são chamados um a um para a balança, na sequência em que se dará o combate. O apresentador chama o primeiro lutador. Ele retira a roupa, sobe na balança: se atinge o peso, faz poses e aguarda o mesmo processo de seu oponente. Quando ambos terminam a pesagem, tem-se a chamada "encarada", um diante do outro para marcar riva- 
lidades e tirar fotos. Os atletas se olham levantando os braços na altura do rosto em uma posição chamada de "guarda" e tentam intimidar o adversário. Depois de alguns instantes nessa posição, eles são separados por um responsável do evento. Imediatamente, buscam seus treinadores para se reidratarem. Estão sedentos, exaustos e eufóricos.

Marcelo cumpriu seu protocolo. Atingiu o peso, fez a encarada, tirou fotos e bebeu sedento o líquido oferecido por Antônio. Estava irreconhecível. Magro, abatido, com os olhos fundos, seu corpo denunciava os maus-tratos dos últimos meses e, sobretudo, da última semana.

Terminada a pesagem, Marcelo voltou imediatamente para o seu quarto no hotel para se reidratar e comer. Ele passou longas horas tomando cerca de dois litros de soro na veia. Quem puncionou a veia foi uma profissional de enfermagem solicitada diretamente pela academia, mas poderia ter sido qualquer outra pessoa sem uma qualificação técnica, que se predisponha a fazê-lo (incluindo um lutador).

“Já ganhei a primeira luta”, disse-me Marcelo ao apontar sua sobrevivência, o que entendemos ser um processo tão penoso quanto lutar. No momento da reidratação, no quarto do lutador, compunha a cena alguns familiares e lutadores da academia, além da comissão técnica. Apesar de aparentemente mais disposto após receber o primeiro litro de soro, Marcelo trazia estampado no rosto o cansaço. Embora os elogios recebidos pelos presentes fossem importantes, ele parecia querer ficar só, dormir e comer. Mas ele precisava suportar um pouco mais; aliás, as pessoas estavam ali para lhe dar "forças" para o combate.

\section{O casca-grossa e combate}

O dia da luta finalmente chega e, com ela, o desejo de vencer a qualquer custo, nem que para isso o atleta pudesse se arriscar a uma lesão séria (fraturas, concussão cerebral, desmaios). A derrota significava fraqueza, infantilidade, incompetência e ser "menos homem” do que o adversário. O oposto do casca-grossa é aquele que se submete, passivo, que tem medo, que se desespera. Por isso, o dia da luta é o momento de mostrar toda a masculinidade possível. Não há espaço para a dor e o receio. A vitória, a força e a necessidade de "lutar até a morte" estavam no discurso de todos os atores.

Marcelo entra no Octógono ao som de um rap nacional, parecendo hipnotizado pelo momento. Ele segue todo o ritual do combate: entrada, fiscalização do corpo, abraços na equipe, entrada no octógono, oração. Seu adversário faz o mesmo e logo a luta começa. Há gritos e assovios na torcida. Foram trinta segundos estudando os golpes do adversário, trinta segundos em ataques iniciais e, em mais trinta segundos, seu oponente foi nocauteado no chão. Marcelo não teve nenhuma lesão. A torcida o ovacionou: "Monstro"; "Atropelou o cara"; "Casca-grossa". O locutor televisivo igualmente correspondeu aos gritos da torcida, afirmando que Marcelo tinha um futuro brilhante no UFC, que era "um cara duro", "focado" e que não "baixava a cabeça para oponente nenhum".

\section{O "humano" pede passagem no pós-luta.}

As primeiras comemorações foram feitas no Octógono e depois nos bastidores, com a equipe e com os vários jornalistas e demais profissionais que por ali transitavam. O corpo 
exausto marcava o fim de um ciclo exitoso e abria caminho para outras lutas e oportunidades (patrocínios, entrevistas). Lágrimas e uma respiração aliviada e profunda. Mas, depois das práticas que o tornaram um trabalhador precarizado, como um astro que inspirava pessoas e se tornava um super-herói para fãs e mídia, ou ainda o casca-grossa que tudo deveria suportar durante o combate, "restou" a volta a sua condição de humano comum.

Depois do combate, Marcelo, exausto pelos meses intensos vividos, voltou para sua casa no interior de São Paulo. Ele pediu permissão à organização do evento para sair mais cedo do que o protocolo dizia, deu mais algumas entrevistas, e foi autorizado a voltar para casa. Foi até o estacionamento, pegou o seu carro e voltou dirigindo sozinho. Nenhum pedido de autógrafo, nenhuma câmera ligada, nenhuma foto. Apenas ele, seu carro, a rua e o sentimento de "missão cumprida". Fora dos limites do espetáculo, ou distante dos fãs e admiradores de MMA, o atleta voltava a ser um "humano comum".

\section{Discussão - O lutador múltiplo}

Quem são os lutadores de MMA nas fases de um camp? Essa indagação e suas possíveis respostas causaram estranhamento e inúmeras dúvidas, razão pela qual fomos instigadas a conduzir esta pesquisa. Os rótulos atribuídos aos lutadores os posicionavam frequentemente como agressivos, desumanos, indisciplinados e cruéis. Com isso, a multiplicidade é transformada em singularidade e redução, colocando as versões em um mesmo plano.

Inspiradas por versões totalizadoras de atleta, convivemos intensamente com Marcelo, um lutador de MMA que atuava profissionalmente no UFC, em dezembro de 2014. Convivemos com diversos atores, humanos e não-humanos, e práticas das quais fomos autorizadas de algum modo participar. Essas versões de atletas foram produzidas e estabilizadas por práticas que fizeram parte da presente discussão.

Tentou-se aqui fugir do realismo das ciências, já que se entende que não existe uma realidade exterior que está em algum lugar para ser desvelada, descoberta, analisada. A realidade só é possível de ser compreendida a posteriori das práticas. Ela não existe por si só, independentemente das diferentes ações (Mol, 2002; Law \& Mol, 2008; Latour, 2012). Assim, as versões de atleta aqui descritas só existem porque as ações, compostas por humanos e não-humanos, as "fizeram ser", não como meros sujeitos objetivados, estabilizados e definidos, mas sim como produtos de práticas que são situadas em um tempo, espaço e culturas específicas. Deste modo, os sujeitos não são objetivados, mas sim as práticas em que estiveram presentes (que, por sua vez, geraram as versões aqui desenvolvidas).

Não se trata de dizer que o atleta, Marcelo, é passivo perante os acontecimentos, se deixando levar pelas práticas das quais se inseriu. Ele atua, modifica a realidade, se posiciona e se vincula simetricamente a diferentes atores. Tal como nos apontam Law e Mol (2008), um ator não age sozinho, mas sim (e sempre) em relação a outros atores, vinculados a eles. Isso significa que também está sendo sempre atendido. A ação própria e a ação dos demais caminham juntas e nunca está totalmente no controle de um ator em particular.

Notou-se aqui que o atleta de MMA é "mais do que um”: um trabalhador, um ídolo, um sobrevivente, um casca-grossa e um "humano-comum”. Ainda que ele também seja "menos do que muitos", já que suas versões são estão totalmente desconectadas, sendo 
coordenadas de algum modo entre si. Podemos pensar que o "nome" (lutador de MMA) é uma primeira ponte entre as versões de atletas, já que é ele quem une, independentemente das práticas em que está envolvido, fazendo com que as diferentes versões não se fragmentem completamente. E como versões distintas, que se reúnem em torno do mesmo nome (lutador de MMA), podem coexistir? Tentaremos responder a esta pergunta baseada em alguns modos de ordenação proposto por Mol (2002): distribuição, adição e inclusão.

O processo de "distribuição" nos mostra que a circulação das versões ocorre em locais específicos e momentos determinados, dando ares de "pacificação" entre as versões, desde que uma não tente ocupar o lugar da outra. Assim, temos o lutador na prática do treinamento como trabalhador precarizado, nas práticas no hotel como "ídolo" que recebe tratamento glamoroso e é assediado pelos fãs e mídia, nas práticas da desidratação como sobrevivente que beira o limite da vida e não parece causar maiores estranhamentos, nas ações da luta como o "casca-grossa" que precisa superar os medos e dores para combater e, na ação de volta para casa, como "humano-comum", que pode dirigir seu carro longe dos controles do camp. Ou seja, assim distribuídas, as diferentes versões podem coexistir sem ser contraditórias, sem dar a ideia de que se trata de um atleta diferente. Sem ser totalmente fragmentado.

Outro modo de coordenação é a "adição", em que diferentes versões são unidas e formam um todo, apontando que os lutadores "são" muitos. Ele é um trabalhador precarizado que muitas vezes recebe bem menos do que o necessário para sua alimentação mensal. Ele é o ídolo que precisa se relacionar com os fãs e a mídia para vender uma imagem atrativa e potente. Ele é um sobrevivente de um camp que tem rigores militares, que o faz viver muito próximo ao limite da vida. Ele é o casca-grossa que parece não sentir dor e medo no dia da luta. E ele é o cidadão comum com suas "normalidades" na volta para casa. Essas várias versões formam o lutador de MMA.

O dia do combate é uma prática em que podemos examinar a adição. Embora seja o dia em que a versão do casca-grossa esteja em evidência, não é possível desconsiderar a sobreposição das demais versões existentes. $\mathrm{Na}$ adição, as diferentes práticas e locais de atuação são alinhados e somados de tal modo que passam a se referir a um objeto único (Cordeiro \& Spink, 2014).

Não há uma hierarquia entre as versões, isto é, uma mais potente que a outra. A "inclusão" nos ajuda a pensar que as versões se inserem mutuamente, embora possam, por vezes, parecer incompatíveis entre si. Ou ainda, um "A" que inclui "B”, e um "B" que inclui “A”, nos poupando de ter que definir qual versão predomina ou é mais "importante”. A inclusão nos ajuda a discutir que não faz sentido a tentativa de criar hierarquias ou colocar os holofotes em determinadas versões. Não sendo uma questão de gradação, é impossível decidir qual versão é mais importante do que a outra, já que sempre há interdependência entre elas e, com isso, interferência.

Nos treinamentos, na recepção do hotel, nas entrevistas e no combate há a tentativa de fragmentação do lutador entre o ídolo e o casca-grossa. Isso ocorre porque pode não ser nada atrativo naquele espaço ter uma versão de lutador precarizado com o mesmo estatuto dessas versões comercialmente robustas. Ainda assim, com a tentativa de fragmentação, lá estão outras versões de atleta, juntas no mesmo objeto.

Atletas são feitos em diferentes práticas, são distintos, ainda que de algum modo relacionados entre si. As versões se relacionam e uma interfere na outra. Desse modo, a interrogação "quem é o atleta de MMA nas fases de um camp?" não tem uma resposta única 
e estabilizada. Se algo deixar de ser feito, se for excluído ou incluído algum ator humano ou não-humano, nas diferentes práticas, uma versão de lutador também poderá deixar de existir. É importante igualmente considerar que os atletas geram efeitos em várias outras práticas sociais.

Pretendemos com este estudo abrir novas possibilidades de entendimento sobre os humanos que lutam MMA, tentando fazer alguma diferença para as práticas nas quais eles estão inseridos. Pretendemos também contribuir para as práticas da Psicologia do Esporte, trazendo novas reflexões e problematizações acerca desses atletas múltiplos, assim como novos modos de se relacionar com eles. Nesse sentido, também são defendidas novas possibilidades de atuação que, podem se chocar com as lógicas essencialistas que visam explorar apenas uma versão de humanos que lutam. Explicitamente, nosso projeto político pleiteia o enfraquecimento de versões totalizadoras que endossam apenas um tipo de lutador, desconsiderando todas as complexidades e modos que "o fazem" ser.

\section{Referências}

Awi, F. (2012). Filho teu não foge à luta. Rio de Janeiro: Intrínseca.

Alonso, M. \& Nagao, S. (2013). Do vale tudo ao MMA: 100 anos de luta. Rio de Janeiro: Editora PVT.

Bracht, V. (2005). Sociologia crítica do esporte: uma introdução. Ijuí, RS: Editora Ijuí.

Bernick, C., Banks, S., Phillips, M., Lowe, M., Shin, W., Obuchowski, N., \& Modic, M. (2012). Practice of Epidemiology Professional Fighters Brain Health Study: Rationale and Methods. American Journal of Epidemiology, 178(2), 280- 286.

Bledsoe, G. H., Hsu, E. B., Grabowski, J. G., \& Brill, J. D. (2006). Incidence of Injury in professional Mixed Martial Arts competitions. Journal of Sports Science and Medicine, 136-142.

Bourdieu, P. (1983). Como é possível ser esportivo? In Questões de sociologia (pp. 136-153). Rio de Janeiro: Marco Zero.

Camilo, J. A. O. (2016). Trabalhador, ídolo, sobrevivente, "casca-grossa" e humano: um estudo sobre versões de atletas de Mixed Martial Arts. Tese de Doutorado, Programa de Pós-graduação em Psicologia Social, Pontifícia Univesidade Católica de São Paulo, São Paulo.

Caillois, R. (1990). Os jogos e os homens: a máscara e a vertigem. Lisboa: Cotovia.

Camilo, J. A. O. \& Spink, M. J. P. (2018). Las Artes Marciales Mixtas (MMA): deporte, espectáculo y economía. Revista de Artes Marciales Asiaticas, 13(1), 20-34.

Cordeiro, M. P. \& Spink, M. J. P. (2014). A multiplicidade da Psicologia Social Brasileira. Athenea Digital, 14(1), 289-300.

Deloitte (2011). Muito além do futebol. Estudo sobre esportes no Brasil. São Paulo. Recuperado de http:// fbf.org.br/ckfinder/userfiles/pdf/Pesquisa_Esportes_Deloitte_2011__Apresentacao_completa. pdf

Franchini, E. \& Vecchio, F. B. D. (2011). Estudos em modalidades esportivas de combate: estado da arte. Rev. Bras. Educ. Fís. Esporte, 25, 67-81.

Kochhar T., Back D. L., \& Mann B., S. J. (2005). Risk of cervical injuries in mixed martial arts. American Journal of Epidemiology, 178(2), 444-448.

Latour, B. (2000). Ciência em ação. São Paulo: Unesp. 
Latour, B. (2012). Reagregando o Social. Salvador/Bauru: Edufba.

Law, J. (2002). Objects and Spaces. Theory, Culturer, Society, 19(5/6), 91-105.

Law, J., \& Mol, A. (2008). The actor-enacted: Cumbrian sheep in 2001. In C. Knappett \& L. Malafouris (Eds.), Material Agency: towards a non-anthropocentric approach (pp. 57-77). New York: Springer.

Méllo, R. P., Spink, M. J., \& Mincoff, V. (2016). Redes em conexão com a Teoria Ator-Rede na Psicologia no Brasil. Psicologia E̊ Sociedade, 28(3), 423-432.

Merced, M. J. (2016). U.F.C. Sells Itself for \$4 Billion. The New York Times, p. B1. New York. Recuperado de http://www.nytimes.com/2016/07/11/business/dealbook/ufc-sells-itself-for-4billion.html? $\mathrm{r}=1$

Mol, A. (2002). The body multiple: ontology in medical practice. Durham, UK: Duke University Press.

Norma regulamentadora n. 24 (NR-24), de 17 de setembro de 1993. (1993). Estabelece Condições Sanitárias e de Conforto nos Locais de Trabalho. Brasília, DF: Ministério do Trabalho e Previdência Social.

Ozanian, M. (2014). The Forbes Fab 40: The World's Most Valuable Sports Brands 2014. Recuperado de http://www.forbes.com/sites/mikeozanian/2014/10/07/the-forbes-fab-40-the-worlds-mostvaluable-sports-brands-2014/\#d0100c016769

Rubio, K. (2001). O atleta e o mito do herói: o imaginário esportivo contemporâneo. São Paulo: Casa do Psicólogo.

Rubio, K. (2010). Jogos olímpicos da era moderna: uma proposta de periodização. Revista Brasileira de Educação Física e Esporte, 24(1), 55-68.

Rubio, K. (2018). Esporte e Mito. São Paulo: Laços

Spink, M., Medrado, B., \& Mello, R. (2002). Perigo, probabilidade e oportunidade: a linguagem dos riscos na mídia. Psicologia: Reflexão e Crítica, 15(1), 151-164.

Wacquant, L. (2000). Putas, escravos e garanhões: linguagens de exploração e de acomodação entre boxeadores profissionais. Mana, 6(2), 127-146.

Wacquant, L. (2002). Corpo e Alma: notas etnográficas de um aprendiz de boxe. Rio de Janeiro: Relume Dumará.

Wells, G. (2012). Mixed Martial Arts: Ultimate Fighting Combinations. Minneapolis: Lerner Publications Company.

\section{JULIANA APARECIDA DE OLIVEIRA CAMILO \\ https://orcid.org/O000-0003-3369-2878}

Possui graduação em Psicologia pela Universidade São Francisco (2003), aprimoramento em Psicanálise no Hospital Geral pelo Instituto Sedes Sapientiae (2004), mestrado e doutorado em Psicologia (Psicologia Social) pela Pontifícia Universidade Católica de São Paulo. Atualmente é professora da Pontifícia Universidade Católica de São Paulo, nos cursos de Administração e Psicologia e professora titular da Universidade Paulista, no curso de Psicologia e Gestão.

Endereço institucional: Pontifícia Universidade Católica de São Paulo. Faculdade de Economia, Administração, Contabilidade e Atuária. Rua Ministro de Godói. Perdizes. 05014-901. Sao Paulo/SP, Brasil E-mail: jacamilo@pucsp.br 


\section{MARY JANE PARIS SPINK \\ https://orcid.org/0000-0003-1672-505X}

Professora Titular da Pontifícia Universidade Católica de São Paulo (PUCSP); docente e orientadora dos Cursos de Mestrado e Doutorado do Programa de Estudos Pós-graduados em Psicologia Social da PUCSP; coordenadora do Núcleo de Pesquisa em Práticas Discursivas e Produção de Sentidos, desde 1987 (Grupo de Pesquisa cadastrado no CNPq). Possui doutorado em Psicologia Social - University of London (1982) e estágio Pós-doutoral em Ciências Humanas na University of Cambridge, Inglaterra (1998). Bolsista de Produtividade do CNPq, desde 1998.

E-mail: mjspink@pucsp.br

Submissão em: 05/10/2016

Revisão em: 05/11/2018

Aceite em: 01/02/2019

Financiamento: este trabalho contou com a "Bolsa Dissídio", destinado aos trabalhadores da PUCSP, e com o auxílio parcial ao seu desenvolvimento via FUNDASP - Plano de Incentivo à Pesquisa Capacitação Docente (PIPEq), Processo 385/2015.

Consentimento de uso de imagem: Não se aplica. 